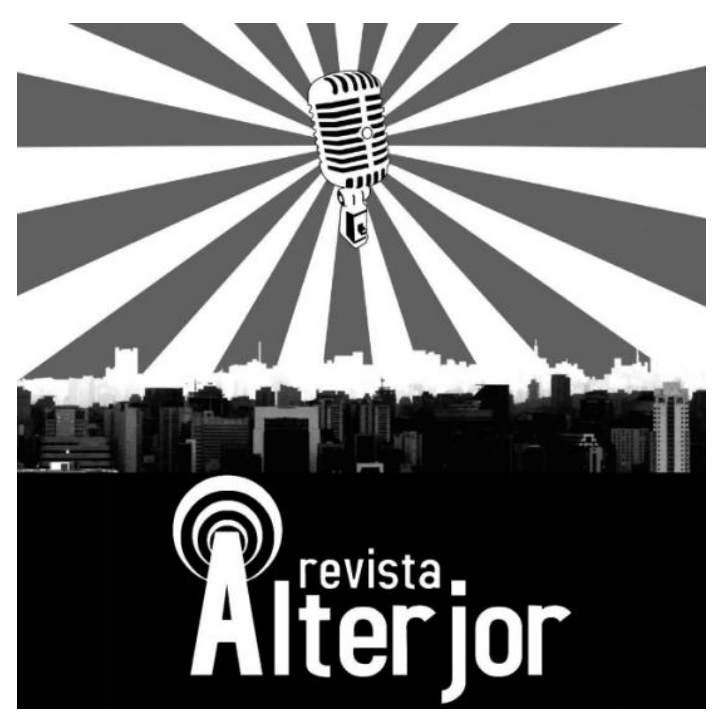

\title{
O AUTOMÓVEL COMO NÃO LUGAR: CONSTRUINDO UM SIGNIFICADO PARA O FETICHE DA MERCADORIA, DO JORNALISMO ESPORTIVO AO JORNALISMO AUTOMOTIVO
}

\author{
Sergio Robinson Quintanilha ${ }^{1}$
}

\begin{abstract}
RESUMO: O significado do automóvel foi reconfigurado pelas corridas de carro e depois pelo fordismo, acentuando o valor simbólico que carrega como mercadoria. Utilizando conceitos de fetiche em Marx e de supermodernidade em Augé, o autor passeia pelas relações do automóvel com o espaço para mostrar a divisão que houve no jornalismo especializado em carros. Na sociedade do excesso, enquanto o jornalismo esportivo cobre o automobilismo, que ele mesmo inventou, ao jornalismo automotivo cabe decifrar a ressignificação do automóvel.
\end{abstract}

PALAVRAS-CHAVE: Automóvel. Fetiche. Supermodernidade. Jornalismo. Comunicação.

ABSTRACT: The meaning of the automobile was reconfigured by car racing and later by fordism, accentuating the symbolic value it carries as merchandise. Using concepts of fetish in Marx and supermodernity in Augé, the author walks through the relationship between the automobile and space to show the division that occurred in specialized car journalism. In the society of excess, while sports journalism covers motorsport, which itself had invented, automotive journalism must decipher the automobile resignification.

KEYWORDS: Automobile. Fetish. Supermodernity. Journalism. Communication.

\footnotetext{
${ }^{1}$ Mestre em Comunicação pela Faculdade Cásper Líbero. Doutorando em Comunicação na ECA-USP. Email: pixmidia@gmail.com
}

Revista ALTERJOR

Grupo de Estudos Alterjor:Jornalismo Popular e Alternativo (ECA-USP)

Ano 10 Volume 02 Edição $22 \quad$ Juhlo-Dezembro de 2020

Avenida Professor Lúcio Martins Rodriģues, 443, Cidade Universitária, São Paulo, CEP: 05508-020 


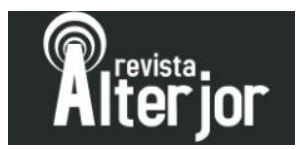

\section{Introdução}

Ao construir circuitos fechados para as corridas de carro, o automobilismo criou lugares específicos para a demonstração de capacidade técnica dos fabricantes e de perícia dos pilotos. $\mathrm{O}$ automobilismo se tornou uma ponte entre o jornalismo especializado e o fetiche da mercadoria automóvel. As corridas de carro deram um sentido ao fetiche e deslizaram para uma posição que fez do próprio automobilismo um produto que usa o seu criador e ao mesmo tempo é usado por ele. Como veremos neste artigo, aqui temos criador e criatura - o jornalismo como criador, o automobilismo como criatura. O automóvel é a matéria que os une. Ele não precisa do jornalismo para ser adorado como um fetiche. Como toda mercadoria, o automóvel já nasceu como fetiche. Porém, foi por iniciativa da indústria de jornais que os carros ganharam um lugar especial para demonstrar seu papel social e ainda captar a mística de homens intrépidos para fazer valer a máxima "vença no domingo, venda na segunda". 2

O surgimento dos autódromos foi um divisor de águas. Estava criado um lugar para consumir automobilismo. Um lugar para adoração do fetiche. Entretanto, esse lugar, que surgiu na modernidade do início do século XX, pode ser considerado um não lugar na supermodernidade do século XXI. Depois que o termo pós-modernidade se tornou ineficaz para definir as transformações da sociedade - uma vez que negava a previsibilidade e a solidez da modernidade, mas não explicava os fenômenos da sociedade que emergiu na última década do século $\mathrm{XX}$-, vários sociólogos buscaram um termo mais apropriado. Bauman (2001) adotou a metáfora da "modernidade líquida". Beck (2018) trata da "metamorfose do mundo" em seu livro post-morten. Augé (2010) fala em supermodernidade. Apesar de guardar algumas coincidências com a modernidade líquida de Bauman, a supermodernidade de Augé baseia-se principalmente no excesso. E o excesso cria não lugares em abundância.

A supermodernidade reúne três figuras do excesso: a "superabundância factual", a "superabundância espacial" e a "individualização das referências" (Augé, 2010, p.

\footnotetext{
${ }^{2}$ A frase original win on Sunday, sell on Monday é atribuída a Bob Tasca, revendedor da Ford nos EUA, em associação ao programa de competições da marca nos anos 1960. A frase se tornou um lema para explicar o forte envolvimento da indústria automobilística nas corridas de carro na época. O fenômeno é explicado no livro The Tasca Ford Legacy: win on Sunday, sell on Monday, de Bob McClurg.
} 


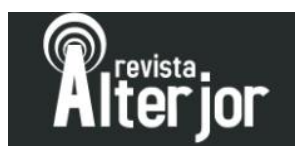

41). Em sua introdução a uma antropologia da supermodernidade, Augé observa que a relação dos indivíduos com espaços constituídos para o transporte, o trânsito, o comércio e o lazer (aeroportos, terminais rodoviários, autoestradas, trevos rodoviários, shopping centers, hotéis, parques temáticos) acabam transformando esses locais em não lugares. Vistos de maneira ampla, nesses locais os indivíduos viajam, compram e repousam, porém os não lugares fazem a mediação de um conjunto de relações consigo (e com os outros) que só dizem respeito indiretamente a seus fins. Para Augé (2010, p. 87), "assim como os lugares antropológicos criam um social orgânico, os não lugares criam tensão solitária".

Os lugares antropológicos são espaços com um repertório histórico, que foram classificados e promovidos a "lugares de memória" por etnólogos, portanto ocupam um lugar circunscrito e específico. Já os não lugares são espaços que não podem ser definidos "nem como identitário, nem como relacional, nem como histórico" (Augé, 2010, p. 73). Simplificando, os não lugares são lugares de passagem, de não permanência, mas não apenas isso, como veremos adiante.

Se a mobilidade é uma necessidade real dos animais (racionais e irracionais), com o desenvolvimento da economia capitalista, o que era uma necessidade física do indivíduo e da espécie acabou se transformando em uma necessidade de um determinado modo de produção (que precisa fazer circular mercadorias, mão de obra e capital) e essa necessidade do modo de produção foi atendida na forma de uma indústria de desejos. Em poucas palavras: a mobilidade é uma necessidade do capitalismo e se expressa como um desejo do sujeito humano. Ao descrever a mercadoria, Marx (1968, p. 41-42) afirma que ela satisfaz necessidades humanas de qualquer espécie, cujas origens podem estar no estômago ou na fantasia. Vista à luz do século XXI, a definição marxiana de mercadoria dá sentido às transformações que ocorreram na mobilidade. A fantasia a que se referia Marx tornou-se, ela própria, uma nova mercadoria. Afinal, fabricar para o desejo tornou-se muito mais rentável do que fabricar para a necessidade.

Para explicar a mudança no significado do automóvel na sociedade capitalista e suas relações com a comunicação num aspecto mais amplo, e com o jornalismo especializado numa visão específica, utilizamos os conceitos de fetiche da mercadoria 


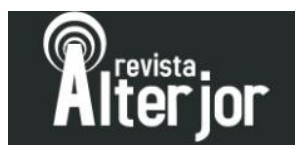

em Marx, de modernidade líquida em Bauman e de supermodernidade em Augé. Antes de tudo, porém, precisamos voltar à origem das corridas de automóvel. Graças a elas, o automóvel se tornou um ícone do fetiche da mercadoria.

\section{Um fetiche com significado}

Karl Benz inventou o automóvel, em 1886. ${ }^{3}$ Mas quem inventou o automobilismo não foi a indústria de carros e sim a indústria de jornais. ${ }^{4}$ As primeiras corridas de automóveis aconteceram por iniciativa de periódicos franceses. E já em sua gênese é possível observar um olhar social da mídia em relação ao automobilismo. A primeira competição de automóveis da história teve como objetivo não a velocidade e o triunfo do alto rendimento do homem e da máquina, como é hoje, mas sim o equilíbrio construtivo entre a mecânica e a segurança para utilização da sociedade. Em 19 de dezembro de 1893, por iniciativa do editor Pierre Giffard, Le Petit Journal de Paris anunciou um prêmio de cinco mil francos franceses para o veículo "não perigoso", "fácil de conduzir" e "não muito custoso de manter" que cumprisse um percurso de 126 quilômetros entre as cidades de Paris e Rouen, na França, num tempo máximo de oito horas e meia (Cimarosti, 1990, p. 14). No dia 30 de abril de 1894, quando foram encerradas as inscrições, 102 veículos com diferentes formas de tração - como motores a vapor ou elétricos - haviam se candidatado ao prêmio. Desses, somente 25 compareceram à prova eliminatória do dia 19 de julho de 1894. Quatro foram desclassificados. Finalmente, no dia 22 de julho de 1894, o Concours des Voitures sans Chevaux reuniu 21 carros sem cavalos na competição que é considerada a pedra fundamental do automobilismo esportivo.

Os carros partiram com um intervalo de 30 segundos um do outro. Um De-DionBouton a vapor foi o primeiro veículo a abrir vantagem e chegou em primeiro lugar em

\footnotetext{
${ }^{3}$ O Benz Patente-Motorwagen foi construído em 1885 e patenteado em 1886 pelo engenheiro alemão Karl Benz. Antes disso, em 1769, o francês Nicolas-Joseph Cugnot havia fabricado um carro movido por motor a vapor.

${ }^{4}$ Este texto faz uma atualização das datas publicadas no artigo Os caminhos da divulgação científica de automobilismo nas revistas brasileiras. Sugiro aos pesquisadores que atentem para este detalhe. Disponível em <https://www.revistas.usp.br/alterjor/article/view/138446>. Acesso em 25 mai. 2020.
} 


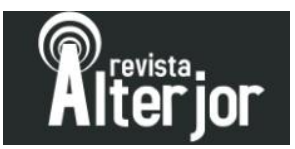

Mantes-la-Jolie, etapa intermediária do percurso. Nem todos conseguiram completar a primeira etapa. Além do De-Dion-Bouton a vapor, um total de treze carros Peugeot e Panhard-Levassor, todos equipados com o motor Daimler ${ }^{5}$ de três a quatro cavalos de poitência, completaram a prova em Rouen. A média de velocidade da prova foi de 17 $\mathrm{km} / \mathrm{h}$ e a máxima alcançada foi de $20 \mathrm{~km} / \mathrm{h}$. O prêmio do Petit Journal foi dividido entre um Peugeot Type 5 e um Panhard-Levassor. Os juízes decretaram que os veículos de duas marchas eram "leves e manobráveis", bem como "de grande interesse". Já o DeDion-Bouton a vapor foi considerado "muito volumoso e pesado" (Cimarosti, 1990, p. 15). Apesar de ter chegado em $11^{\circ}$ lugar com seu Peugeot Type 5 número 27, o engenheiro Louis Rigoulot é cultuado no Museu da Aventura Peugeot, em Sochaux, França, como o vencedor da primeira competição de carros da história, oito anos depois da invenção do automóvel.

Mas a comunidade do automobilismo não considera a prova Paris-Rouen uma corrida de carros. A primeira corrida oficial aconteceu somente no dia 15 de junho de 1895, no trajeto Paris-Bordeaux-Paris, um percurso de 1.200 quilômetros. Mas, também nessa ocasião, teve o jornalismo envolvido, pois o comitê organizador da prova contou com a participação de representantes de vários jornais franceses e de alguns membros do Touring Club de France. Desse grupo surgiu o Automóvel Clube da França (ACF), fundado em 12 de novembro de 1895. O regulamento da primeira corrida oficial de automóveis exigia que a prova fosse cumprida no máximo em 100 horas. Nem precisou tanto. Após 48h48min, um Panhard-Levassor cruzou a linha de chegada com uma média de 24,1 km/h, seguido de um Peugeot e de um Benz. Devido ao longo percurso da prova, foi a primeira vez que um carro utilizou rodas equipadas com pneus, por questão de conforto. Ao volante estava André Michelin (Cimarosti, 1990, p. 15).

Para o objetivo das primeiras corridas, os percursos de estrada eram suficientes. As competições - ainda que não oficiais - se espalhavam. Na Itália, a primeira competição ocorreu em 18 de maio de 1895 (pouco antes da primeira corrida oficial na França), e reuniu cinco veículos num percurso de 93 quilômetros de ida e volta entre Turim e Asti. Só três completaram a prova: um Daimler Omnibus de quatro lugares,

\footnotetext{
${ }^{5}$ Motor de combustão interna, inventado pelo engenheiro alemão Gottlieb Wilhelm Daimler. 


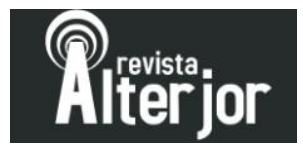

coberto, e duas motocicletas. Do outro lado do Atlântico, nos EUA, a primeira competição automobilística americana aconteceu em Chicago, no dia 2 de novembro de 1895, organizada pelo jornal Times Herald. Houve muitas inscrições, mas apenas dois carros compareceram para a largada: um Benz e um Duryea (veículo criado pelo próprio condutor). Só o Benz conseguiu percorrer os 150 quilômetros do percurso, após 8h44min (Cimarosti, 1990, p. 15).

Em 1900 surgiu o conceito de circuitos fechados, porém ainda em estradas. O primeiro foi o Circuit du Sud-Ouest, que tinha 335 quilômetros de extensão. Tratava-se de um contorno da cidade de Pau, França, tendo nos extremos leste e oeste as localidades de Tarbes e Bayonne. Os dois primeiros lugares ficaram com a Panhard. Ainda em 1900, novamente uma iniciativa editorial colocou o automobilismo em um nível superior. O editor americano James Gordon Bennet, que vivia em Paris, criou a primeira categoria do automobilismo. A fórmula Gordon-Bennet exigia que os carros tivessem um peso entre 400 e 1.000 quilos (sem pilotos, combustível, óleo, água, acumuladores de energia, utensílios, peças sobressalentes, bagagem e alimentação). Os veículos deveriam ter dois lugares (para piloto e copiloto) e todas as peças deveriam ser do país de origem do carro. As corridas deveriam ter no mínimo 550 quilômetros e no máximo 650 quilômetros. Gordon Bennet enviou convites para os automóveis clubes da França, Alemanha, Inglaterra, Itália, Bélgica, Suíça, Áustria e EUA, mas cada um só poderia ter três marcas competindo. Coube ao Automóvel Clube da França a organização da primeira corrida, um percurso de 570 quilômetros entre Paris e Lion. Novamente a vitória ficou com um Panhard-Levassor, em 9h09min, com a média de 62,1 km/h (Cimarosti, 1990, p. 17).

Com o aumento das médias de velocidade, as corridas se tornaram mais perigosas. Acidentes sérios aconteceram. Assim, por questões de segurança, hipódromos foram improvisados para abrigar corridas de automóvel. Os primeiros circuitos de carros do mundo surgiram nos EUA, exatamente como adaptações de hipódromos já existentes: o de Milwaukee (construído nos anos 1870) foi reformado para os automóveis em 1903; o de Nashville (construído em 1891) foi reformado em 1904. O primeiro circuito construído com a finalidade de abrigar corridas de carro foi o 


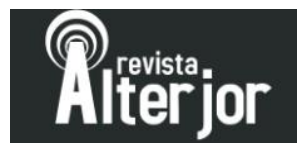

de Brooklands, em Surrey, Inglaterra, inaugurado em 17 de junho de $1907^{6}$. A pista tinha 4,43 quilômetros de extensão e utilizava a reta de um aeródromo, mas manteve o tradicional formato oval nascido com a utilização dos hipódromos.

Quando as corridas foram transferidas para os circuitos fechados, finalmente os carros passaram a percorrer centenas de quilômetros para chegar a lugar nenhum, como ponteiros de um relógio. Essa modificação no ambiente das corridas e a fórmula introduzida por Gordon Bennet propiciaram o nascimento de um novo conceito: o

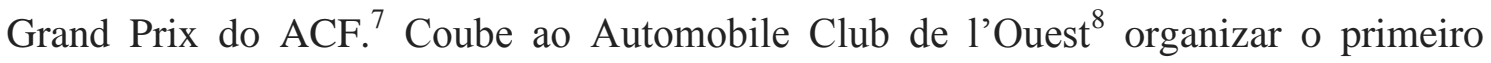
Grand Prix, nos dias 26 e 27 de junho de 1906. ${ }^{9}$ O percurso total era de 1.236 quilômetros, porém constituído de 12 voltas de 103 quilômetros no circuito de La Sarthe, que ficava ao leste de Le Mans (seis voltas em cada dia, com pausa durante a noite). O novo regulamento determinava um peso máximo de 1.000 quilos. O consumo de combustível era limitado em 30 litros por 100 quilômetros. "A prova, muito severa, foi ainda mais exigente pela poeira que, como em todas as corridas da época, causou grandes problemas, uma vez que a estrada não era asfaltada e sim de terra batida" (Cimarosti, 1990, p. 23).

Depois de doze anos sendo impulsionado por iniciativas editoriais, finalmente o automobilismo de competição ganhou vida própria - mas ainda assim contando com a promoção do jornal esportivo francês L'Auto. Ao contrário da Copa Gordon-Bennet, que limitava a participação de cada país em três construtores, no novo formato todos podiam se inscrever. Doze marcas participaram: Fiat, Itala, Mercedes, De Dietrich, Renault, Darracq, Brasier, Gordon-Brillé, Panhard, Hotchkiss, Clement-Bayard e Grégoire. O novo conceito também atraiu os melhores pilotos da Europa, que passaram

\footnotetext{
${ }^{6}$ Historic England. Disponível em: <https://historicengland.org.uk/listing/the-list/list-entry/1020137>. Acesso em 04 mai. 2020.

${ }^{7}$ Embora apareça nos anais como $9^{\circ}$ Grande Prêmio do ACF, a corrida de 1906 é considerada a primeira da fórmula que popularizou as corridas de Grand Prix, precursora dos grandes prêmios de Fórmula 1. Naquele ano, o Grand Prix passou a ter um valor de 100 mil francos franceses ao vencedor e foi aberto a todos os fabricantes de automóveis.

${ }^{8}$ Organizador da famosa 24 Horas de Le Mans.

${ }^{9}$ Em 1968, o Grande Prêmio do ACF passou a se chamar Grande Prêmio da França (Cimarosti, 1990, p. 215).
} 


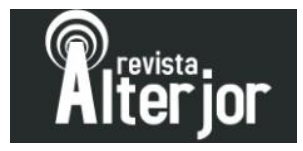

a rivalizar em fama com os carros que dirigiam. A vitória coube ao húngaro Ferenc Szisz, com um Renault AK que usava motor de 13 litros com $90 \mathrm{cv}$ de potência ${ }^{10}$. Ele levou pouco mais de 12 horas para completar as 12 voltas, a uma velocidade média de pouco mais de $100 \mathrm{~km} / \mathrm{h}$. Szisz realizou 19 trocas de pneus nos dois dias da prova (Spurring, 2015, p. 19). Com a vitória, as vendas de carros da Renault passaram de 1.600 unidades em 1906 para 3.000 no ano seguinte e para 4.600 unidades em 1908 (Rendall, 1993, p. 49). De alguma forma, o lema "vença no domingo, venda na segunda" já era uma realidade.

Embora não fosse mais dependente das ideias da indústria editorial, o automobilismo continuou a beber na fonte do jornalismo. E foi no circuito de La Sarthe, o mesmo que representou a independência do Automóvel Clube da França em relação aos jornais, que a dobradinha automobilismo-jornalismo novamente vingou. Segundo Bernucci (2015, p. 26), a motivação dos inventores das 24 Horas de Le Mans - a mais tradicional corrida de longa duração do mundo - foi "colocar os carros à prova e contestar a publicidade dos veículos da época". A iniciativa partiu do jornalismo - mais exatamente de três diretores do jornal Roue Fil. Um deles, Emile Coquile, era um crítico ferrenho dos automóveis da época. "Na opinião de Coquile, os veículos não obedeciam aos itens de segurança e desempenho apresentados pela publicidade que as marcas veiculavam, e via na competição de resistência o cenário ideal para contestar as propagandas" (Bernucci, 2015, p. 26). A primeira edição das 24 Horas de Le Mans aconteceu em 1923 e até hoje essa corrida atrai todos os grandes fabricantes que desejam mostrar ao mundo a tecnologia e a resistência de seus carros.

A criação de um lugar para a realização das corridas, mesmo nas de longa duração, como as 24 Horas de Le Mans, foi fundamental para transformar o automobilismo em mais uma "mercadoria" do capitalismo, pois permitiu que o espetáculo passasse a ser exibido e vendido. No formato original as corridas atraíam interesse do público, mas os espectadores que viam a largada não tinham contato visual

\footnotetext{
${ }^{10}$ Os motores atuais mais populares costumam ter entre um e dois litros de capacidade, com potência similar ou maior.
}

Revista ALTERJOR

Grupo de Estudos Alterjor:Jornalismo Popular e Alternativo (ECA-USP)

Ano 10 Volume 02 Edição $22 \quad$ Juho- Dezembro de 2020

Avenida Professor Lúcio Martins Rodrig̉ues, 443, Cidade Universitária, São Paulo, CEP: 05508-020 


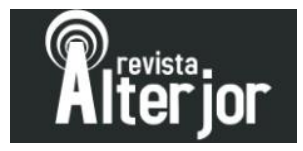

com carros e pilotos ao longo da prova - no máximo, podiam ver também a chegada, quando se tratava de um percurso de ida à volta.

Ao se transformar em "mercadoria" (não física, mas consumível), o automobilismo deu sentido ao fetiche. O automóvel não perdeu sua porção fantasmagórica, como se referia Marx, mas ganhou um sentido. Com as corridas, era possível não apenas possuir o fetiche, mas também “torcer" por ele. Ao longo do tempo, as corridas em autódromos trouxeram todos os elementos de consumo real ou imaginário para os fãs. Foi possível consumir alimentos, bebidas, bonés, camisetas, chaveiros, jaquetas, relógios, óculos, canetas, miniaturas, cartazes, livros, fotografias e todos os itens necessários para "aproximar" os fãs de seus carros e pilotos preferidos. Mas, acima de tudo, também foi possível atender ao consumo imaginário dos que se viam representados pelas histórias de carros, pilotos e demais sujeitos das corridas.

\section{Fetiche em Marx}

Logo no início de O Capital, Marx (1968, p. 41) descreve a mercadoria como "um objeto externo, uma coisa que, por suas propriedades, satisfaz necessidades humanas, seja qual for a natureza, a origem delas, provenham do estômago ou da fantasia". E complementa: "Não importa a maneira como a coisa satisfaz a necessidade humana, se diretamente, como meio de subsistência, objeto de consumo, ou indiretamente, como meio de produção" (Marx, 1968, p. 41-42). O Capital foi publicado em 1867.

Foi em outra obra, Manuscritos econômico-filosóficos, de 1844, que Marx usou a palavra alienação para designar o estranhamento do trabalhador com o produto de seu trabalho. Por não participar de todas as fases de fabricação e por não dominar os meios de produção, o trabalhador via a mercadoria não como uma obra sua, mas como uma espécie de feitiço. Marx buscou inspiração na passagem bíblica que mostra os seguidores de Moisés insatisfeitos com a longa jornada pelo deserto e adorando um bezerro de ouro. Esse "novo deus" foi chamado de fetiche. Segundo Marx, para o homem moderno, as mercadorias haviam deixado de ser um produto humano para se 


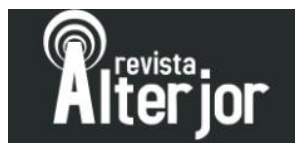

tornarem obras de adoração. Para ele, "a mercadoria é misteriosa simplesmente por encobrir as características sociais do próprio trabalho dos homens".

Uma relação social definida, estabelecida entre os homens, assume a forma fantasmagórica de uma relação entre coisas. Para encontrar uma símile, temos que recorrer à região nebulosa da crença. Aí, os produtos do cérebro humano parecem dotados de vida própria, figuras autônomas que mantêm relações entre si e com os seres humanos. É o que ocorre com os produtos da mão humana, no mundo das mercadorias. Chamo a isto de fetichismo, que está sempre grudado aos produtos do trabalho, quando são gerados como mercadorias. É inseparável da produção de mercadorias. (Marx, 1968, p. 81)

Não é nosso objetivo aqui entrar na discussão da crítica marxista do capitalismo, mas sim trazer o conceito de fetiche da mercadoria para o entendimento do significado do automóvel durante mais de um século de existência e sua recente transformação.

$\mathrm{O}$ aspecto fantasmagórico da mercadoria identificado por Marx muito antes do advento do fordismo, em 1913, a aceleração do tempo na modernidade líquida, a supressão do espaço físico para a circulação de notícias e o fortalecimento da imagem como "motor" de muitos campos (político, econômico, industrial, cultural, jornalístico) resultaram numa sociedade em que o excesso passou a ser o padrão. Excesso de consumo, excesso de trabalho, excesso de angústia, excesso de produção, excesso de carros, excesso de trânsito, excesso de notícias, excesso de imagens.

É justamente na sociedade do excesso que o fetiche do automóvel como mercadoria ficou escancarado. Se o carro fosse vendido por seu valor de uso (que seria a locomoção), o preço de uma Ferrari 488 seria muito mais próximo ao de um Fiat Uno, por exemplo. Porém, se Marx admitia "uma relação física entre coisas físicas", também observava que até a mais barata das mercadorias adquire vida própria e passa a ser comercializada por seu valor de troca e não por seu valor de uso: “A forma mercadoria e a relação de valor entre os produtos do trabalho, a qual caracteriza essa forma, nada tem a ver com a natureza física desses produtos nem com as relações materiais dela decorrentes" (Marx, 1968, p. 81).

Revista ALTERJOR

Grupo de Estudos Alterjor:Jornalismo Popular e Alternativo (ECA-USP)

Ano 10 Volume 02 Edição $22 \quad$ Juho- Dezembro de 2020

Avenida Professor Lúcio Martins Rodrig̉ues, 443, Cidade Universitária, São Paulo, CEP: 05508-020 


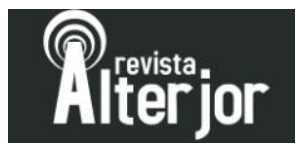

Por isso, até mesmo carros muitos populares, como o Ford T ou o Volkswagen Fusca, sempre foram vendidos por seu valor de troca, que é resultado das relações sociais e não do custo real da matéria-prima e do trabalho do operário que o monta. A crescente robotização das linhas de montagem acentuou ainda mais o fetiche da mercadoria automóvel. O consumo explodiu e hoje temos 85 milhões de carros vendidos no mundo. ${ }^{11}$ Para dar conta da superprodução automobilística, o fordismo não foi suficiente. ${ }^{12}$ Foi preciso também adotar o toyotismo ${ }^{13}$ e a automação das fábricas, em substituição ao trabalho lento e nem sempre constante dos operários. Até mesmo os trabalhadores que ficam no final da linha de montagem são responsáveis somente pela instalação de um equipamento ou pela checagem dos principais sistemas do carro. Num ritmo constante, o automóvel surge diante de cada operário como uma mágica, como obra de um sistema que o montador não domina, como se fosse um "feitiço" do capitalismo. Marx nem sequer precisou conhecer a linha de montagem (que só surgiria 46 anos após a publicação de $O$ Capital) para enxergar seus efeitos na sociedade moderna.

\section{Supermodernidade em Augé}

Na supermodernidade, a história transcorre em ritmo acelerado: "Apenas temos o tempo de envelhecer um pouco e nosso passado já vira história, nossa história individual pertence à história" (Augé, 2010, p. 29). Deslocar-se do ponto A ao ponto B, portanto acelerar o tempo para percorrer um determinado espaço entre dois pontos, é a função primordial do automóvel. Com as corridas automobilísticas, como vimos, o carro ampliou seu significado. Foi nas corridas que o automóvel passou a ser associado

\footnotetext{
${ }^{11}$ Segundo o site Guia do Carro, a consultoria Focus2Move informa que a venda anual de carros chegou ao recorde de 93,6 milhões em 2017. Disponível em: <https://www.terra.com.br/parceiros/guia-docarro/china-derruba-mercado-global-de-carros-para-85milhoes,a7d25cfe8617a9422b495683322e2439guo3rjvs.html>. Acesso em: 21 mai. 2020.

${ }^{12}$ Segundo a revista Quatro Rodas, a produção em série foi a inovação mais importante da indústria automobilística e ela continua a ser aperfeiçoada continuamente. Disponível em: <https://quatrorodas.abril.com.br/noticias/a-evolucao-das-linhas-de-montagem-de-automoveis/>. Acesso em 24 dez. 2019.

${ }^{13}$ Produção no modelo just-in-time, ou seja, a fabricação e distribuição num ritmo coordenado que impede a escassez do produto ou a criação de grandes estoques.
} 


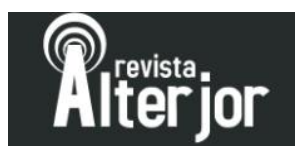

a um novo paradigma: ser conduzido pelo motorista, ao invés de conduzir o motorista. Por isso, nas competições, não bastava ao carro suas qualidades técnicas, como a potência do motor e a durabilidade de seus componentes mecânicos. Ao ser conduzido, o carro precisou ser modificado para permitir que o homem que o conduzia o fizesse, preferencialmente, de forma eficiente, confortável e segura. Não bastava ao automóvel o deslocamento espacial - era preciso também oferecer ao condutor a possibilidade de fazê-lo com destreza.

Foi nas corridas automobilísticas que o automóvel se desenvolveu tecnicamente e passou a buscar um eterno compromisso entre fatores que brigam entre si: velocidade e resistência, potência e consumo, estabilidade e conforto, prazer e segurança. Com esses oito compromissos antagônicos, quatro de um lado e quatro de outro, o automóvel passou a ter dezenas, centenas, milhares de configurações - desde o tamanho das rodas e a largura dos pneus até a posição dos instrumentos, passando pelo formato dos bancos e pelos materiais utilizados em sua fabricação. $\mathrm{O}$ resultado disso foi uma das indústrias mais poderosas do planeta, com todos os seus efeitos colaterais.

Uma vez que as novidades tecnológicas competiam com a perícia dos melhores pilotos pelas principais manchetes jornalísticas, a cobertura de automobilismo atraiu naturalmente os veículos especializados em motores, notadamente as revistas automobilísticas, como Auto Motor und Sport (Alemanha) e Road \& Track (EUA), e mais tarde as brasileiras Quatro Rodas e Autoesporte. ${ }^{14}$ Esse movimento se fortaleceu com o advento da Fórmula 1, em 1950, e a consequente criação de um campeonato mundial de automobilismo substituindo as corridas de Grand Prix. A partir da metade da década de 1950, a concepção dos carros de Fórmula 1 se afastou do paradigma dos carros comuns. A preocupação com a segurança perdeu espaço para a inventividade dos construtores de carros de corrida. Era preciso ser cada vez mais rápido nos autódromos, ainda que isso custasse a vida de dezenas de pilotos, o que aumentou o fascínio dos fãs pelas corridas. Por questões de segurança dos usuários, a indústria de carros de passeio não pôde trilhar o mesmo caminho. Com isso, o que era um assunto só passou a ser

14 Quatro Rodas (Editora Abril) foi fundada em 1960; Autoesporte começou a circular em 1964 pela Efecê Editora e desde 1998 pertence à Editora Globo. Ambas abandonaram a cobertura de automobilismo e dedicam quase a totalidade da cobertura às novidades da indústria automobilística. 


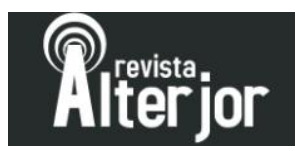

dois. O automobilismo se tornou um braço do jornalismo esportivo. Por outro lado, a cobertura especializada da indústria de veículos produzidos em série precisou de um novo termo: jornalismo automotivo. Como já tratamos da história da cobertura esportiva em outro artigo (Quintanilha, 2018), vamos seguir a partir daqui com o jornalismo especializado em carros de série, ou seja, o jornalismo automotivo.

Augé inclui o automóvel em suas descrições de não lugares, mas o faz de forma indireta, referindo-se a ele nas viagens, nas estradas, nos trevos rodoviários e nos estacionamentos coletivos. Isso depende da relação de cada indivíduo, porém a tensão é sempre individual, jamais coletiva. Pode haver multidões, mas o sentimento não é uniforme - este é o ponto levantado por Augé. O automóvel é em sua essência um não lugar, mas não para todos. De tanto ser usado, é possível que o carro proporcione significados históricos a um piloto de corridas, a um motorista comum, a um chofer de táxi ou até a uma família inteira. A atualização constante de modelos, porém, para atender à necessidade de obsolescência programada (da mercadoria) pelo capitalismo, passou a dificultar a relação histórica entre o automóvel e seus usuários. Essa obsolescência forçada, muito mais relacionada a aspectos visuais do que mecânicos, faz com a troca de carro ocorra mais por desejo, por busca de status, do que por quebra de algum componente. Sob o ponto de vista dos consumidores, essa constante procura pelo "novo" impede que alguém seja feliz com seu carro por muito tempo. Sob o ponto de vista dos fabricantes, isso possibilita grandes volumes de produção, mas também exige uma eterna vigilância nas tendências para não continuar produzindo uma mercadoria "obsoleta".

Entretanto, há um grupo cada vez mais numeroso de consumidores, notadamente jovens residentes nas grandes cidades, que "possui" um automóvel na palma da mão a qualquer momento, por meio de aplicativos como Uber e 99. Para esses consumidores, que podem somar 25\% em 2030, segundo pesquisa da Bright Consulting, ser feliz com o próprio carro está longe de ser uma prioridade.

Nesse ambiente, o automóvel tem cada vez mais dificuldades de criar um vínculo afetivo com seus usuários. Assim, passa a ser apenas mais um objeto tragado pelo buraco negro da supermodernidade, que cria novos não lugares e de lá eles não 


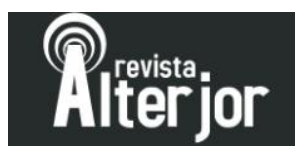

saem. O carro então pode ser caracterizado como um fetiche em ruínas, sem significado para uma parcela da população, e apresenta-se como mais um exemplo de não lugar. A indústria vive do imaginário, do sonho da liberdade de ir e vir, da fantasia da mobilidade sem limites, da colagem do sujeito no objeto (Lacan, 1967), mas, perante as jovens gerações, percebe-se um avanço da caracterização do automóvel como não lugar.

Perder as novas gerações é péssimo. Mas antigos adoradores do fetiche também estão se cansando da incessante atividade de comprar-vender-escolher-comprar-venderescolher um novo carro. Essa atividade, que no século XX era um prazer, no século XXI tornou-se uma obrigação, quase uma tortura mental. Com excesso de ofertas no mercado, com um ritmo alucinante de lançamentos, os consumidores ficam sempre em dúvida se fizeram ou não um bom negócio. É aí que recorrem aos especialistas e muitas vezes saem ainda mais confusos, pois, ao contrário dos jornalistas que faziam a cobertura das primeiras corridas de automóveis, no final do século XIX e nas primeiras décadas do século XX, os jornalistas da supermodernidade mal têm tempo de noticiar uma novidade e já existe outra e outra e outra. Há ocasiões em que três ou quatro modelos são lançados na mesma semana - e é rara uma semana sem novidade ao longo de um ano.

Sem relação histórica com os usuários, o automóvel torna-se, portanto, um não lugar. Um lugar de passagem. E o carro comum, aquele que a classe média pode comprar, vai perdendo a fantasia. Sobram os carrões. O carro encarece porque ganha cada vez mais conteúdos eletrônicos que permitem ao usuário rodar conectado. Por isso, a indústria já vende carros até com Wi-Fi a bordo, numa tentativa de dar ao motorista e aos passageiros a sensação de que o automóvel é uma extensão de sua casa ou de seu escritório, situação muito bem observada no sistema dos objetos de Baudrillard (2019, p. 73): "Com efeito é o campo privado da habitação que reúne a quase totalidade de nossos objetos cotidianos. O sistema todavia não se esgota no interior doméstico. Comporta um elemento exterior que constitui por si só uma dimensão do sistema: o automóvel".

Apesar do rápido deslocamento do automóvel, de ícone do fetiche a não lugar da supermodernidade, a narrativa jornalística especializada permanece fundamentada no 


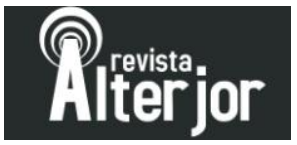

fetiche, alheia a essa ressignificação. Publica-se uma superabundância de informação sobre todos os lançamentos do mercado, com testes instrumentados, impressões ao dirigir, comparativos com produtos similares ou simples descrições do objeto de desejo. Também é facilmente verificável a profusão de mídias presentes nessa narrativa do fetiche, com youtubers obtendo mais popularidade do que antigas revistas especializadas ou influenciadores digitais competindo com a audiência dos suplementos especializados dos jornais. Temos aqui um problema gerado pela superabundância factual. Afinal, "a densidade factual das últimas décadas ameaça suprimir todo e qualquer significado" dos acontecimentos em curso, quaisquer que sejam eles, observa Augé (2010, p. 31).

Mas, e o novo significado do automóvel, se é que existe um? Para as pessoas que passam horas em marcha lenta no trânsito engarrafado das grandes cidades, o automóvel é o habitáculo de uma experiência nada prazerosa, que mais se assemelha à cela de uma prisão do que ao símbolo de liberdade analisado por Baudrillard (2019, p. 74-75).

Para o motorista engarrafado, queimando combustível fóssil enquanto seu carro anda-e-para-anda-e-para, num balé enfadonho e inútil, o automóvel é um não lugar, pois o trânsito congestionado é só uma barreira em busca de um espaço livre. O carro é um não lugar porque o motorista não consegue e não quer criar vínculos emocionais ou raízes enquanto se arrasta pelo trânsito - a maioria busca um lugar mental ouvindo música ou notícias no rádio. E mesmo quando desliza em velocidade por uma rodovia livre o automóvel nada mais é do que um componente do não lugar chamado estrada, onde milhares se deslocam porque só estão ali de passagem. "O espaço do viajante seria, assim, arquétipo do não lugar" (Augé, 2010, p. 81).

O termo "espaço", em si mesmo, é mais abstrato do que o de "lugar", por cujo emprego referimo-nos, pelo menos, a um acontecimento (que ocorreu), a um mito (lugar-dito) ou a uma história (lugar histórico). Ele se aplica indiferentemente a uma extensão, a uma distância entre duas coisas ou dois pontos [...] ou a uma grande temporalidade ("no espaço de uma semana"). (Augé, 2010, p. 77) 


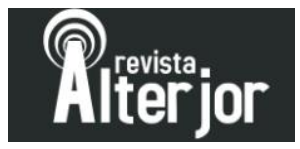

O carro conectado é a forma que a indústria encontrou de dizer aos consumidores que eles podem manter o contato com o mundo externo enquanto passam por não lugares ou enquanto estão presos ao não lugar motorizado. Na feira Tokyo Motor Show de 2017, a Nissan apresentou o protótipo de um carro autônomo ${ }^{15}$ em que o próprio veículo se transforma em sala de estar ou em escritório se o motorista assim o desejar. Os principais fabricantes da indústria automobilística investem em pesquisa e desenvolvimento de carros autônomos para que o motorista possa se libertar da tarefa de dirigir quando quiser.

Todavia, por mais conectado e autônomo que seja, o automóvel não consegue despir-se de sua fantasia na supermodernidade: a do não lugar que tenta dar ao usuário a ilusão de pertencimento ao mundo exterior. Afinal, quando estão em trânsito, motorista e passageiros entram em uma espécie de universo paralelo, no qual a conexão por bluetooth tenta manter um fio de relação com o mundo externo, enquanto o sistema de áudio toca músicas ou lê mensagens de WhatsApp. Mas essa ilusão de pertencimento ao mundo exterior pode acabar quando a tela do Waze ou do Google Maps informa o tamanho do congestionamento à frente ou quando uma rádio qualquer avisa que o trânsito engarrafado vai durar mais meia hora. O automóvel então mostra sua condição na espacialidade. "Esse lugar que fixa sem ter ponto fixo" não pode ser geograficamente demarcado por ser "voltado para o consumo", portanto, "sua materialidade é a pura circulação" (Bucci, 2019, p. 8-9).

Para os milhões de adoradores do fetiche, dentro de um automóvel é possível passar momentos prazerosos, seja por causa da companhia ou simplesmente por estar a bordo daquele carro especial ou desejado. Mas mesmo aquele carro nunca será um lugar de permanência, por isso ele é na essência um não lugar. Durante mais de 100 anos os fabricantes vêm injetando símbolos e fantasias nele, mas, de dentro do carro, os signos reais que os ocupantes veem são informações de trânsito nas placas ou nos painéis luminosos sobre os lugares (ou não lugares) que estão buscando. Esse é o motivo pelo qual o antropólogo francês considera o percurso rodoviário duplamente notável.

\footnotetext{
${ }^{15}$ Nissan IDS Concept.

Revista ALTERJOR

Grupo de Estudos Alterjor:Jornalismo Popular e Alternativo (ECA-USP)

Ano 10 Volume 02 Edição $22 \quad$ Juho- Dezembro de 2020

Avenida Professor Lúcio Martins Rodriģues, 443, Cidade Universitária, São Paulo, CEP: 05508-020
} 
Ele evita, por necessidade funcional, todos os lugares memoráveis dos quais nos aproxima: mas os comenta; os postos de serviço somam-se a essa informação e se dão, cada vez mais, ares de casas da cultura regional, propondo alguns produtos locais, mapas e guias que poderiam ser úteis a quem parasse ali. Mas justamente a maioria daqueles que passam não param; eles passam de novo, eventualmente, todo verão ou várias vezes ao ano; de modo que o espaço abstrato que são regularmente levados a ler mais do que a olhar torna-se, a longo tempo, familiar para eles. (Augé, 2010, p. 90)

Também é simbólico da atribuição de não lugar ao automóvel a diferença de comportamento dos usuários de ônibus, trem urbano ou metrô e de carros compartilhados, em aplicativos como o Waze Carpool. ${ }^{16}$ Dentro de um ônibus, trem ou metrô, as pessoas sabem que estão em um espaço público e não se sentem obrigadas a se relacionar com as pessoas próximas. $\mathrm{Na}$ carona compartilhada, as pessoas estão dentro de um carro e isso "sugere" que elas conversem entre si. Segundo relatos de usuários desse tipo de mobilidade, as experiências podem ser constrangedoras, pois a carona compartilhada é a única coisa que os une. ${ }^{17}$ Nesses casos, o não lugar tem suas características ruins potencializadas.

Apesar de todas essas situações, as montadoras vendem o automóvel como símbolo de liberdade, status e poder. Quase nunca se vê dois carros na mesma peça publicitária. No mundo imaginado pelos publicitários, aquele carro específico é o dono do mundo. Há sempre um caminho deserto e um automóvel dando sentido a alguma coisa. Há um casal. Há família. Há romantismo. Há aventura, esportividade, liberdade. Quase nunca há outros carros. Porém, uma vez adquirido aquele carro, aquele objeto de desejo, aquele fetiche, a supermodernidade bate à sua cara. $\mathrm{O}$ excesso se faz presente na forma de trânsito, de impostos, de radares controlando a velocidade, de guardas rodoviários, de multas, de itens de manutenção. Existe uma abundância de compromissos para manter um automóvel, mas eles nunca aparecem nas peças

\footnotetext{
${ }^{16}$ No Waze Carpool, as pessoas se cadastram para dar ou pegar carona. Quem dá a carona, recebe uma quantia em dinheiro. Quem pega a carona, paga. Os valores são menores do que os de aplicativos como Uber e 99.

${ }^{17}$ Segundo conversas do autor com usuários do Waze Carpool em 2019.
} 


\section{Preitior}

publicitárias, tampouco na maioria das reportagens de avaliação do jornalismo automotivo.

Para os especialistas e aficionados, o carro é prazeroso. Não são poucas as pessoas que passam os fins de semana em track days nos autódromos, acelerando seus possantes em pistas fechadas especialmente para pilotos amadores. São nesses não lugares que motoristas comuns vestem a fantasia de um piloto de competição e o automóvel volta a ter o mesmo significado que tinha nas pioneiras corridas, como a Paris-Bordeaux-Paris. Também há um público que consome viagens ou competições leves organizadas pelas próprias montadoras ou por clubes de fãs. Seja de carro normal, de moto ou de veículo 4x4 (para caminhos difíceis), os clubes automotivos são ao mesmo tempo uma fonte de renda para as montadoras e uma válvula de escape para os proprietários de autoveículos. Eles realmente usufruem dessa liberdade controlada. Então, por algumas horas, o automóvel, mesmo sendo um não lugar, transforma-se em símbolo de liberdade e prazer. Até que surja a próxima segunda-feira e um novo engarrafamento. $\mathrm{O}$ sonho então se evapora. $\mathrm{O}$ carro passa a ser apenas um não lugar.

\section{Considerações Finais}

O espaço não é dado. O espaço nunca foi dado. Ele é produzido. Seja por corpos celestes, por explosões, pela comunicação ou pela política, o espaço é fabricado. O Brasil ganhou esse nome apenas em 1527; portanto, não existia em 1500, quando foi "descoberto", ou 300 anos antes. Existia outra coisa, que não era o Brasil. Tampouco em 1494, quando o país foi dividido pelo Tratado de Tordesilhas. O Brasil foi dividido antes de existir politicamente, o que é mais uma demonstração de que o paradigma da circulação é que define o sentido do espaço (Bucci, 2019).

O automóvel como conhecemos não existia em 1884. O carro existia, mas ainda era puxado por cavalos ou movido a vapor. O automóvel, em sua concepção moderna, é um espaço que foi inventado em 1885 e patenteado em 1886. Um espaço que se move. E neste movimento, modifica os espaços que ocupa. Modificou os hipódromos, transformando-os em autódromos. Modificou as estradas, as ruas. Modificou o próprio

Revista AL TERJOR

Grupo de Estudos Alterjor: Jornalismo Popular e Alternativo (ECA-USP)

Ano 10 Volume 02 Edição $22 \quad$ Juho- Dezembro de 2020

Avenida Professor Lúcio Martins Rodrig̉ues, 443, Cidade Universitária, São Paulo, CEP: 05508-020 


\section{Preiejer}

jornalismo sobre automóveis, quando acrescentou ao paradigma da mobilidade o paradigma da velocidade. Um espaço que, mesmo sendo um não lugar, transpassou seu próprio significado como mercadoria, afetando não apenas os modos de produção, a partir do fordismo, mas também o jornalismo especializado. A pura divisão entre jornalismo esportivo para cobrir o automobilismo e jornalismo automotivo para cobrir a indústria de carros já não é suficiente para explicar o fenômeno.

Se os não lugares são o espaço da supermodernidade, esta não pode pretender as mesmas ambições que a modernidade (Augé, 2010, p. 101). Portanto, se as ambições do automóvel se mantiveram firmes na passagem da modernidade sólida para a modernidade líquida, na supermodernidade elas são outras. O carro precisa manter seu fetiche ao mesmo tempo em que precisa ser apenas útil. O que temos, portanto, é o congestionamento de uma ideia. Cabe à comunicação especializada decifrar esse enigma, pois ela também é afetada por ele. O ponto de partida é investigar se o fetiche da mercadoria ainda é suficiente para sustentar esse modelo de jornalismo.

\section{Referências}

AUGÉ, Marc. Não lugares: introdução a uma antropologia da supermodernidade. $8^{\mathrm{a}}$ ed. Campinas: Papirus, 1994.

BAUDRILLARD, Jean. $O$ sistema dos objetos. $5^{\text {a }}$ edição. São Paulo: Editora Perspectiva, 2019.

BAUMAN, Zygmunt. Modernidade líquida. Rio de Janeiro: Zahar, 2001.

BECK, Ulrich. A metamorfose do mundo. Rio de Janeiro: Zahar, 2018.

BERNUCCI, Cleber. Contra a publicidade da época. Racing. São Paulo, p. 26, n. 334, mai. 2015.

BUCCI, Eugênio. Ubiquidade e instantaneidade no telespaço público: algum pensamento sobre a televisão. Revista Caligrama, São Paulo, v. 2, n. 3, 2007. Disponível em: <http://www.revistas.usp.br/caligrama/article/view/ 64692>. Acesso em: 23 dez. 2019.

Fabricação de valor no imaginário: uma crítica da comunicação. Disciplina do Programa de Pós Graduação em Comunicação da ECA-USP. Em sala de aula, 2019. 


\section{Retiejior}

CIMAROSTI, Adriano. Grand Prix Story: tutti i gran premi del mondo dal 1894 a oggi. Milano: Giorgio Nada Editore, 1990.

MARX, Karl. O Capital: crítica da economia política. Vol. 1, Livro 1: O processo de produção capitalista. Rio de Janeiro: Civilização Brasileira, 1968.

LACAN, Jacques. A lógica do fantasma. In: Seminário XIV, 1966-1967, sessão de 12 abr. 1967.

QUINTANILHA, Sergio. Os caminhos da divulgação científica de automobilismo nas revistas brasileiras. Revista Alterjor, v. 17, n. 1, p. 109-125, 15 jan. 2018. Atualizar.

RENDALL, Ivan. The Chequered Flag: 100 years of Motor Racing. London: Weidenfeld \& Nicolson, 1993.

SPURRING, Quentin. Le Mans: 1923-29 Yeovil, Somerset: Haynes Publishing, 2015. 